\title{
Toward a Ghance Management View of Organizational Change
}

\author{
Runtian Jing ${ }^{1}$ and Andrew H. Van de Ven ${ }^{2}$ \\ ${ }^{1}$ Shanghai fiao Tong University, China, and ${ }^{2}$ University of Minnesota, USA
}

ABSTRACT Chance serves as the gate to organizational change. Based on a relational view of chance, we propose that in an organizational context, the chance to change is affected by the perceptions of change agents and the affordance of situational momentum, and that different time points of change are associated with different degrees of chance favorability. We develop a theoretical model to represent how change agents can assess the favorability of current and future momentum and how they can benefit from identifying a perceived chance by employing chance grasping, entraining, creating, or riding strategy to promote organizational change. We generate theoretical propositions to illustrate the four timing strategies of chance management. The overall contribution of this study is a chance management view of organizational change that considers change agents and situational momentum as two interdependent factors in the process of managing the chance to change.

KEYWORDS chance management, organizational change, situational momentum, timing strategy

Chance favors only the prepared mind.

- Louis Pasteur

A man may have wisdom and discernment, but that is not like embracing a favorable chance.

- Confucius

\section{INTRODUGTION}

Mr. Alfred Sloan encountered a major challenge after becoming the President of General Motors in 1923. The problem was the conflict between the company's production and research divisions over the introduction of air-cooling technology for their engines. The head of the research division, Mr. Charles F. Kettering, devised an air-cooled engine that the former President, Pierre du Pont, considered an upgrade from the water-cooled engine of the time. Although GM suffered serious losses from the introduction of its air-cooled engine due to its immature technology, and although the production division fiercely opposed manufacturing 
it, Kettering was perfectly sure of its future success and was prepared to leave the company should it be shelved.

Based on his own industrial experience, Sloan did not believe in the technical feasibility of the new engine, but he was not prepared to lose Kettering, and more seriously - he wished to maintain continuity with the management of the former President, who considered the air-cooled engine an upgrade for the water-cooled engines of conventional cars. Thus, despite his reservations, Sloan maintained du Pont's vision, funding research into copper piping systems that would improve the air-cooling system. Two years later, as Sloan had predicted, the air-cooled copper engine project was still in development, and the research team was forced to comply with market pressure and revert to the water-cooled engines. Under this circumstance, Sloan reformed the structure of the research division to develop other products. Partially due to Kettering's excellent design genius, many of the later innovations made by the research division significantly supported GM's leading position in the auto industry (Sloan, 1964).

Sloan's example is not atypical. Organizational agents sometimes need to take a chance management view to deal with a change problem. Most literatures of organizational change have addressed the questions of 'what to change' rather than 'when to change' (Huy, 2001; Orlikowski \& Yates, 2002). The dominant theories of planned change assume that the time and plan for change is controlled by change agents (Burnes, 2004). ${ }^{[1]}$ But in reality, a proper chance to change is not always set by managerial intention but by situational momentum, which is defined as the contextual forces enabling organizational change (Jing \& Van de Ven, 2014). When organizations become deeply interconnected with external entities, the pace of internal activities tends to be externally controlled (Pfeffer \& Salancik, 2003). As a result, even planned organizational change entails considerable contingencies, because plans for change are typically ambiguous, involving many different organizational units and people whose interests and approaches often differ and even conflict with each other and thus even the best plans can go awry (Pettigrew, 2012; Van de Ven, Polley, Garud, \& Venkataraman, 1999).

Despite the fact that chance underlies any decision related to the timing of implementing a change process, the organizational change literature seems to have ignored this line of study. Though some studies of social movements (Benford \& Snow, 2000), organizational ecology (Hannan \& Freeman, 1984), and entrepreneurial opportunities (Alvarez \& Barney, 2010; Baron, 2006) highlight the importance of chance, they seldom consider when to seek or create a favorable chance, as we intend to do in this study. Based on the philosophy of Interpretivism, we propose a 'relational' view of chance management. With such a view, we show how change agents can assess the favorability of current and future momentum and how they can benefit from identifying a perceived chance by employing four different timing strategies to promote organizational change.

We begin the article with an explanation of the 'probabilistic' and 'relational' approaches to chance and review how chance has been conceptualized in the 
management literature. Then, we further elaborate on the 'relational' approach of chance management to reveal how the interplay between change agents and situational momentum can present a chance to enact organizational change. Next, we develop four timing strategies for change agents to manage the chance to change and explain three assumptions underlying our theoretical explanation. Finally, we conclude with a discussion of the contributions of the chance management view of organizational change to the existing literature.

\section{THEORETIGAL BAGKGROUND}

\section{'Probabilistic' Approach vs. 'Relational' Approach of Ghance}

The concept of chance always lies in the shadow of people's minds and serves as the 'gate to change' (von Franz, 1980). Based on perceived chance, people try to fit their actions into the rhythm of environmental change (Bandura, 2005).

There are two different approaches to chance in human societies: a 'probabilistic' approach and a 'relational' approach. The 'probabilistic' approach acts as the dominant paradigm in the existing literature, especially in a Western context. The English word 'chance' comes from the Old French word 'chéance', which means 'the way the dice fall'. Merriam-Webster Dictionary defines chance as 'the possibility of a particular outcome in an uncertain situation'. We call this a 'probabilistic' approach, indicating the uncertainty of an event occurring at a particular time. This approach is derived from the philosophy of Positivism, which views chance as inherently unpredictable and unmanageable (Alvarez \& Barney, 2010). In a 'probabilistic' sense, being held responsible and accountable for managing uncontrollable events represents an oxymoron in chance management theory and practice, especially in Western societies. Thus, as Denrell, Fang, and Liu (2015: 924) glaringly captured: 'Management scholars view chance explanations as less compelling than other explanations partly because they seem less useful normatively. We believe this attitude is misguided'.

In contrast, a less-studied yet promising area in the literature is the 'relational' approach of chance, which is more popular in Eastern societies, and especially so in China (Jullien, 2004; Van de Ven \& Jing, 2012; von Franz, 1980). The term 'chance' ('机会') in Chinese means 'a favorable moment to adopt a certain action', indicating that people associate opportunities for taking actions with the development of environmental forces (Tsang, 2004). ${ }^{[2]}$ Such an approach originates from the philosophy of Interpretivism (Zhang et al., 2012), which emphasizes that change agents align the timing and momentum of their actions with shifting internal and external forces for change. ${ }^{[3]}$ This approach can be illustrated by the example of passing the puck in the game of hockey. The great hockey player Wayne Gretzky once said that to catch a good chance to hit the puck, the player needs to 'go to where the puck is going, not where it had been'. In other words, the path of a puck is jointly determined by its momentum and the player's hitting actions. 
Table 1. Probabilistic view vs. relational view of chance

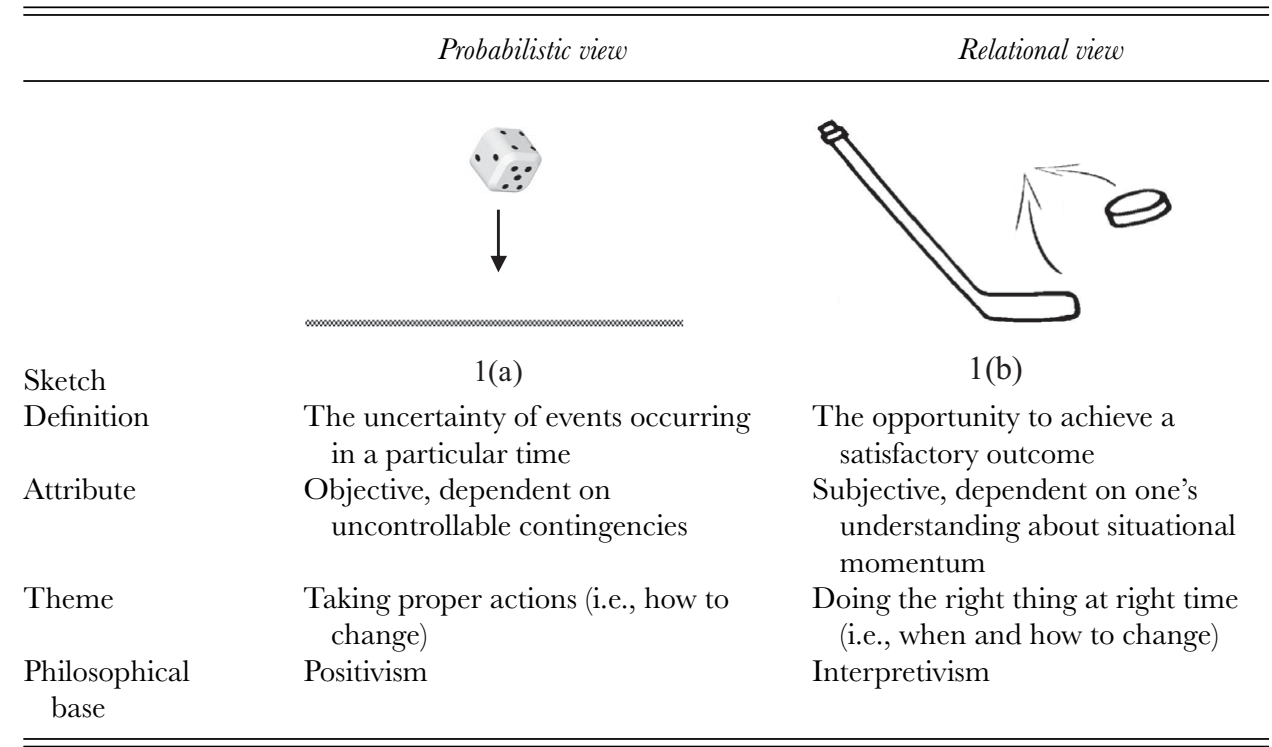

However, the trajectory is not always perfect, since the momentum is constantly redirected by the surrounding environmental forces during the puck's course.

The two approaches are further compared in Table 1. Now suppose there is such a case that change agents have to make an organizational change (e.g., lay off approximately 20 employees) in a firm. If they follow a probabilistic approach, they are aware that their change action may lead to one of many possible outcomes (e.g., success, compromise, or failure) due to disturbance by uncontrollable contingencies (e.g., an employee strike, a labor union's resistance, or a government intervention). Despite the fact that the firm can make plans to overcome potential internal and external disturbances, the change results are often highly uncertain. As shown in sketch 1 (a) of Table 1, this process is just like a dice game. When thrown or rolled, a die will come to rest on the ground, showing on its upper surface a random integer from one to six. However, if change agents follow a relational approach, they know they can achieve a better outcome by comparing the possible results of various timing strategies that could be used to initiate the change. As shown in sketch 1(b) of Table 1, this process is just like a hockey game. The different time points of action are associated with different degrees of chance favorability aided by the varying situational momentums over time. Based on the assessment of alternative actions and outcomes, change agents can select better timing to have a better chance to change.

\section{Chance-Related Research in the Organizational Field}

In the strategy and entrepreneurship literature, the early Austrian economicsinspired view of entrepreneurial opportunities follows the probabilistic approach. 
It is formally addressed as an 'opportunity discovery' view, assuming that opportunities are formed by exogenous shocks to preexisting industries (e.g., changes in technology, consumer preferences, or other environmental attributes), to be discovered and exploited by alert entrepreneurs (Kirzner, 1989).

Organizational ecology theorists embrace a dominant probabilistic approach to chance. They assume that under conditions of uncertainty and ambiguity, there are severe constraints on the ability of individuals to conceive of and implement correct changes that might improve organizations' chances of survival in the face of competition. Thus, 'in a world of high uncertainty, adaptive efforts ... turn out to be essentially random with respect to future value' (Hannan \& Freeman, 1984: 150). A key research stream in this field involves estimating the survival chances of organizations facing certain variations and the rate at which those organizations adopt the variations (Baum \& Shipilov, 2006).

A relational view of chance is emerging in the recent literature about entrepreneurial opportunity creation, which emphasizes that opportunities are formed endogenously by the entrepreneurs themselves through a chance-creating process (Sarasvathy, 2001; Venkataraman, 2003). Here, as Alvarez and Barney (2010: 566) addressed, 'the formation of creation opportunities need not begin with "completely blind" variations. An actor's prior beliefs may not be entirely naive'. For example, in a study of new business ventures, Gersick (1994) revealed that the window of entrepreneurial opportunity is determined not only by the internal readiness of a startup but also by the substantial time limits and schedules dictated by its strategic environment. The success of new product development depends on an intentional match between the speed of product development inside the firm (i.e., internal forces) and the pace of market maturation in the social environment (i.e., external forces).

Those who adopt a relational view of chance argue that probabilities for change are not determined objectively but rather are socially constructed based on the actions of change agents with respect to evolving situations in the environment. As Bandura (2005: 14) stated, 'people can make chance happen by pursuing an active life that increases the number and type of fortuitous encounters they will experience'. In other words, one can increase the odds of encountering a particular chance by learning how to maneuver and practicing relational chance to change.

\section{Definition and Elements of Ghance in the Present Study}

Following the relational approach, we define the chance to change as a favorable moment for change agents to enact organizational change events. ${ }^{[4]}$ Change agents always have criteria (e.g., financial performance, employee satisfaction) to evaluate whether the change results are satisfactory or not. If a momentum-enabled change result is predicted to be acceptable, it indicates a favorable chance to change; otherwise, it is unfavorable. Specifically, we use the following formula to reflect 
the key elements of this concept:

$$
\text { Chance }=F(\text { agents, momentum })
$$

As this formula shows, chance is a function of agents and momentum. Here, change agents are the people who are responsible for enacting the organizational change; momentum refers to change agents' perceptions about the forces to trigger, grasp, or maintain the movement of an organization, which includes two parts, internal momentum and external momentum (Siggelkow, 2001). ${ }^{[5]}$ Internal momentum refers to the forces enabled by the allocation of organizational resources, the development of capabilities, and the process of making commitments to support the change, while external momentum refers to the factors inherent in the changing environment that can facilitate an organizational change process.

As a key concept in the model, momentum provides the foundation for change agents to seize a relational chance. For example, the chance for a driver to pass another car on the road is based on his/her judgment of the relative momentum of the two cars; in the same sense, entrepreneurs need to start their business in a window of opportunity based on their intuition about organizational and environmental change.

Momentum includes internal and external parts. The concept of internal momentum for change is well illustrated in Kurt Lewin's field theory. Inspired by natural laws in the physical world, Lewin (1951) argued that the status quo of organizations exists in a quasi-stationary equilibrium, with some situational forces pushing the organizations in one direction and other counterbalancing forces restraining their movement. An organizational change process is determined by the change agent's use of the relative power of driving and restraining forces. The role of external momentum is well illustrated in Gibson's (1977) affordance theory, focusing on the ecological impacts of agent-situation interaction. As he remarked, 'Just as a motion for the physicist can be specified only in relation to a chosen coordinate system, so is a phenomenal motion relative to a phenomenal framework' (Gibson, 1954: 310). Here, affordance means 'what you make of it,' which can be understood as 'conditions in the environment for constraints to which the agent is attuned' (Greeno, 1994: 336). Different from field theory or affordance theory, the present study examines the chance to change by the combined forces of internal and external momentum, termed as situational momentum in the following sections.

\section{Timing Strategy in Organizational Contexts}

Change agents can tailor their timing strategies to improve their chances of success. As Brown and Eisenhardt (1997) showed in their studies of multiple-product innovation in six firms in the computer industry, successful companies can seize or even create a chance to innovate due to their knowledge and practice of connecting past, present, and future time horizons. With the increasing uncertainty of the business environment, researchers have begun to pay more attention to studies 
Table 2. Four different strategies of chance management

\begin{tabular}{|c|c|c|c|}
\hline \multirow{4}{*}{$\begin{array}{c}\text { Current } \\
\text { Momentum }\end{array}$} & \multicolumn{3}{|c|}{ Anticipated Future Momentum } \\
\hline & & Hostile & Favorable \\
\hline & Hostile & $\begin{array}{c}\text { Chance Creating } \\
\text { Strategy }\end{array}$ & $\begin{array}{c}\text { Chance Entraining } \\
\text { Strategy }\end{array}$ \\
\hline & Favorable & $\begin{array}{c}\text { Chance Grasping } \\
\text { Strategy }\end{array}$ & $\begin{array}{c}\text { Chance Riding } \\
\text { Strategy }\end{array}$ \\
\hline
\end{tabular}

of timing effects in organizational contexts. In addition, timing strategy has been increasingly regarded as an important source for firms to formulate a competitive advantage (Huy, 2001), as with time-based competition (Shang \& Liu, 2011), justin-time production (Sakakibara, Flynn, Schroeder, \& Morris, 1997) or first-mover advantage (Lieberman \& Montgomery, 1998).

As Orlikowski and Yates (2002) noted in their review of research on organizational time, most prior studies have taken an objective perspective toward time, assuming time to be objective and independent of human actions. Recently, research on organizational entrainment (e.g., Ancona \& Chong, 1996; PérezNordtvedt, Payne, Short, \& Kedia, 2008) has begun to turn the research focus to a more subjective perspective of timing. According to this subjective perspective, 'time is experienced through the interpretive processes of people who create meaningful temporal notions such as events, cycles, routines, and rites of passage' (Orlikowski \& Yates, 2002: 689). In describing the subjective perspective, the studies of timing strategy emphasize how organizational actors perceive and adopt strategic timing as a way to improve their performance. The present study takes this subjective perspective, with a focus on timing strategy as an important way for change agents to manage the chance to change.

\section{A PROPOSED MODEL OF GHANGE MANAGEMENT}

As shown in Table 2, we propose that change agents need to recognize a relational chance based on their assessment of current and future momentums. That is, as presented in this $2 \times 2$ model, change agents can adopt one of four timing strategies, i.e., chance grasping, entraining, creating, or riding strategy, as a response to seize or create a favorable chance to change.

\section{Three Premises of the Model}

Notably, there are three premises underlying our exploration of the relational view of chance management. First, there exists a cyclical pattern of environmental 
change. As the philosopher Hegel (1977) argued, the advance of human society is not one of linear progress, but a complex process of development better understood as an ascending spiral. Thus, as found in many studies, changes observed in markets, technologies, and institutional forces often follow a cyclical pattern of progression (e.g., Glasner, 1997; Romanelli \& Tushman, 1994). Some changes occur synchronously with others and are paced even in a predictable pattern (Ancona \& Chong, 1996). The existence of a periodic pattern to environmental changes provides the possibility for the change agents to anticipate the development of situational momentum; otherwise, agents can play only a negligible role in capturing a favorable chance.

Second, a favorable chance is afforded by the situational momentum in supporting a change action. As mentioned above, situational momentum is the combined force of internal and external momentums, and a dynamic match between these two parts along with the temporal dimension can afford different conditions of chance favorability. What currently presents as an impossible change may turn out to be possible after change agents take the changing rhythm of future environment into consideration (Jing \& Van de Ven, 2014). In the beginning case of GM, one research team's insistence on developing a particular technique weakened over time due to increasing market pressures, presenting a favorable chance to reform the research plan.

Third, change agents play important roles, not only in developing a vision for change but also in selecting a favorable chance to implement it. As Kotter (1990) suggested, change agents need to create a vision for organizational change, communicate with their followers of what the organization will look like after the change. Essentially, the alignment of people behind the established vision for change involves considering the desirability of various unattained wishes and goals inside the organization, serving as a desired end-state people are committed to achieve. After vision for change is established and communicated, change agents can plan its implementation by a chance management view. To do so, they need to adopt an implementation-focused reasoning, by specifying various anticipated concrete situations that may afford a different chance to initiate the vision-oriented changes (Gollwitzer, 1999). At this implementation stage, change agents' ability to apprehend and recognize situational momentum is essential for success.

\section{Chance Grasping, Entraining, Riding, and Creating Strategies}

To better grasp the chance to change, change agents need to find and acquire links in time. As shown in Table 2, based on the assessing results of current and future momentum, change agents can take four different strategies of chance management accordingly.

Chance-grasping strategy. When current momentum is favorable but future momentum is perceived to be hostile or unclear, change agents should promptly 
execute the desired change; otherwise, this good opportunity may slip away. This is called a 'chance-grasping strategy'.

For example, Mr. Pan Shiyi, one of the most successful business people in China, is considered to be an 'opportunist' in the real estate industry (Lu, 2012). In 1992, Pan was still poor and he attempted to create his venture with very limited money. One day, when having lunch in the government canteen of Huairou County in Beijing, he heard that the City of Beijing had granted the local county four quotas of joint-stock company with the aim of raising public funds, but no one was willing to invest. Pan had been working in Shenzhen, a frontier city of economic reform, for many years and knew that governmental quota meant money at that time. Therefore, he immediately reached the county leader who was in charge of this project with a proposal to establish a joint-stock company. 'Well, it is okay', the leader replied, 'but you have only one week's time left to finish all the application procedures needed'. Pan did not give up this opportunity. He strove to complete all the application materials on time. As a result, Beijing Wantong Company was founded. Backed by government policy, the new company received a financing quota of 800 million RMB, which bestowed Wantong with a strong competitive advantage among Chinese real estate companies in the 1990s. This case illustrates the essence in the following proposition:

Proposition 1: When current momentum is favorable and future momentum is predicted to be hostile or uncertain, change agents can grasp the available chance by promptly taking change actions.

Chance-entraining strategy. When current situational momentum is unfavorable and change agents insist on prompt change, they are likely to encounter strong resistance (Gilbert, 2005). On these occasions, they should assess the trend of future momentum. When momentum is expected to be favorable in the future, agents can purposefully delay their change actions and be careful to entrain change efforts to align with the rhythm of momentum change. This is called 'chanceentraining strategy.' Here, the term 'entraining' is borrowed from biology, where most behavioral processes are rhythmic or cyclical in nature (Oatley \& Goodwin, 1971). In organizational studies, entraining can be defined as 'the adjustment of the pace or cycle of an activity to match or synchronize with that of another activity' (Ancona \& Chong, 1996: 253).

With the chance-entraining strategy, organizations change the timing of their endogenous activities by adjusting when activities are performed (e.g., phase) and at what rate (e.g., tempo) and try to attune their actions to parallel the favorable chance derived from the periodical pattern of environmental change (Perez-Nordtvedt et al., 2008). For example, during the initial innovation stage of the cochlear implant in 1970s, the activities of product development in this industry were heavily regulated by external forces, such as governmental legislations, regulations, and standards. Under this circumstance, firms should match the 
development of their internal momentum, composed of a product manufacturing and launch plan, marketing activities, and logistic arrangements, with the pace of environmental change (Van de Ven et al., 1999). Otherwise, they may miss the coming opportunities of market bursting. Here, one important implication is that a faster pace of change is not always better in final outcomes. Just as the GM case shows, accelerating the pace may result in change actions seeming illegitimate, which would bring about more negative effects to the organizations. Many attempts of organizational change fail because they are executed in an inappropriate situation over which managers do not have enough awareness and control (Huy, 2001). Stated formally:

Proposition 2: When the situational momentum is currently unfavorable but anticipated to become favorable in the near future, change agents need to entrain their change actions with the changing rhythm of the environment.

Chance-riding strategy. When both current and future momentum are perceived to be favorable, change agents need to consider how to plan and implement the changes over the long term to achieve the best possible outcome; otherwise, they may waste an incredible opportunity. This is called 'chance-riding strategy'.

For example, during the past three years, Mr. Jack Ma, CEO of the Alibaba Company, has carried out a successful organizational transformation by riding the continuous momentum of the growing e-commerce market. Ma proposed the goal to transform his company into a platform organization in 2008, but the internal and external momentum did not afford such a radical change at that time, as the turnover of China's e-commerce market was 2.9 trillion RMB, and only approximately $1.5 \%$ of personal consumption had been transacted online in 2008. In early 2012, Ma realized that the chance for change had come: the continuing growth in e-commerce had created favorable momentum that was anticipated to continue into the future. Thus, in July 2012, Ma decided to divide the company into seven business divisions, including Taobao, Tmall, Juhuasuan, and Ali International. Just as this new structure began running in early 2013, he continued to ride the market momentum to implement a further change, sectioning the business into 25 divisions. In 2013, the turnover of China's e-commerce sales reached 10.2 trillion RMB, and China overtook the United States as the world's largest e-commerce market. Meanwhile, the differentiated form of organizational structure has helped the company capitalize on emerging market opportunities. By the end of 2015, the number of online shoppers in China reached 410 million, approximately five times the number in 2008 , and $15 \%$ of personal consumption was transacted online. As a result of the above change, Alibaba has replaced WalMart as the world's largest retailer, with total sales at 3.1 trillion RMB in 2015.

All change agents need to first set up a vision for change. Nevertheless, in a chance-riding context, change agents need to pay special attention to base their vision development on their open-minded imagination of the future environment. 
They can then carry out a strategic plan to fulfill the vision and explore the market opportunities afforded by current and future favorable momentum (Kotter, 1990). Such a chance-riding change process often aims at sustainable market development from a long-run perspective, which is quite different from the aforementioned profit-driven strategy of a chance-grasping change process. Thus, we propose the following:

Proposition 3: When both current and future momentum are predicted to be favorable, change agents can ride this incredible chance to plan and implement organizational change over the long run.

Chance-creating strategy. In contrast, when both current and future momentum are assessed to be hostile, one choice the agents can make is to consciously affect internal or external forces to redirect situational momentum. From an ecologist's view, different substances and objects of the environment have different affordances for manipulation (Gibson, 1977). This is called the 'chance-creating strategy'. This strategy is driven by the motivation and plan of organizational agents, followed by their actions to perceive and manipulate the environment for a favorable chance.

The organizational change process of Chengdu Bus Group (CBG) provides a good example of chance-creating strategy (Jing \& Van de Ven, 2014). CBG is a large state-owned enterprise providing public transportation services in the city of Chengdu, in China's southwest province of Sichuan. CBG was facing intense competition from three other privately owned bus companies during 2001-2007. Each company wanted to put more buses on the high-profit routes, which then became crowded with too many buses. Since no company had the formal authority to coordinate market competition, a solution to the problem seemed unattainable, causing losses to all companies involved. In 2008, Mr. She Chen was appointed as the new CEO of CBG. To reverse the bad situation, the first decision Chen made was to cut the price of bus tickets in half rather than directly negotiating or aligning with other companies. Such an initiative from CBG forced its competitors to cut down their prices as well, lest their customers quickly desert. Three months later, the other three companies asked CBG to take their equity shares at very low prices since they could no longer afford to compete. After the outside equities had been purchased, CBG arranged the buses and routes for optimization. The overcompetition problem was solved.

As this case shows, chance creation is at least a partially endogenous process for change agents: they first change the ecological factors, then wait for a response to their actions - usually from the enacted environment - and then take further actions once the situational momentum is perceived to be favorable. Therefore, we offer the following proposition:

Proposition 4: When both current and future momentum are perceived to be hostile, change agents can create a chance to change by redirecting the development of internal or external momentum. 


\section{DISGUSSION}

In his review study of planned change, Huy (2001: 617) calls for the examination of 'situational and dispositional characteristics that give rise to change agents' understanding and assumptions about time'. This has been the focus of our study. Based on the relational approach of chance, we elaborate a chance management view of organizational change.

\section{Theoretical Implications}

This study offers an important contribution to the literature of chance management. In the research field of social movements and entrepreneurial opportunity, a key argument is whether chance is discovered or created. In other words, does it objectively exist or is it subjectively constructed? According to the relational approach developed in the present study, we propose that the perception of change agents can inhibit or enhance the identification and pursuit of chance to change. For example, in the case presented at the beginning of the paper, the market trend of the auto industry was beyond the control of GM, but this did not skew Sloan's alertness to seize a favorable chance to reform the research division. Without managerial perceptions and intentions, the changes of internal and external forces become meaningless to an organizational change process. In essence, chance is a favorable moment for the change agents to intentionally associate a certain action with situational momentum. To do so, change agents not only work in, but also work with, the environment. In the CBG case, the change agent created a chance to change by cutting the price of bus tickets in half. The enactment triggered ecological change by affecting customer choice. Therefore, both CBG's enactment and external market forces gradually induced a strong change in the environment, which further redirected the situational momentum for organizational change from hostile to favorable. The essence here is exactly captured by Louis Pasteur's famous saying: 'Chance favors only the prepared mind'.

This study highlights the importance of a momentum-based approach to understand the role of change agents in an organizational context. In organizational change literature, change agents are often granted heroic power and capability, and they control the pace of change by planning and setting goals (Burnes, 2004). As their organizations become more interconnected with external entities, the forces of situational momentum begin to play increasingly important roles in determining the pace of change. Thus, we propose a momentum-based approach to frame the relationship between change agents and internal/external forces. Here, the role of change agents is assumed to be both adaptive and purposeful. Based on what is learned by the organization, the change agent adopts a purposeful solution to the problem in advance, otherwise their assessment of a situation is meaningless or impossible. Just as 
Mintzberg's (1987) potter metaphor illustrates, the awareness of past experiences and future prospects helps people craft a strategy for their next actions. These actions are purposeful. Based on the assessment of situational momentum, change agents entrain their organizational change efforts with the external pace of environmental change. These actions are adaptive, thus, 'temporally capable change agents should be alert to shifting conditions both inside and outside the firm, vary their actions if need be, and zigzag their way to the final destination' (Huy, 2001: 613).

This study also has a theoretical contribution to the literature of resistance or commitment to change. Most of the studies in this literature are designed from the managers' perspective, and employees are commonly regarded as the major sources of change resistance, which needs to be reduced by managerial efforts such as training, education, communication, or participation (Piderit, 2000). Meanwhile, there is substantial evidence that some $70 \%$ of all change initiatives fail (Burnes, 2011). Such a high ratio may indicate that most change initiatives are doomed to fail from the start. In fact, many organizational changes are initiated by the top leaders just to serve their own interests, without enough regard for the affordance of internal and external momentum (Jing, Xie, \& Ning, 2014; Rousseau \& Tijoriwala, 1999). Thus, future research needs to examine the questions of 'when to change' or even 'when not to change'. As this study implies, one important way to improve the momentum and legitimacy for change is to carefully deliberate timing issues of organizational change, and try to associate change actions with a favorable chance. Here, the thesis is that people need to maintain harmony between their actions and situational momentum (Jing \& Van de Ven, 2014).

\section{Managerial Implications}

Due to ever-increasing environmental uncertainty, 'simple linear notions of formulating and implementing strategy of planned change, now have to contend with deeper layers of complexity' (Pettigrew, 2012: 1308). As a general conclusion from this chance management view, change agents need to learn to anticipate the timing of internal and external momentum that will afford change, even though they cannot totally control it. Here are specific managerial implications:

First, change agents vary in their capability to perceive and create the chance to change. Prior studies about organizational chance have not given enough attention to this issue (Denrell, Fang, \& Liu, 2015). Just as in Gretzky's description of skating to where the puck will be, the chance to change is recognizable only to the agents who are able to make sense of contextual change (Johns, 2006). In fact, people vary in their capability to assess and create contexts to support the rationality of their actions, which is not simply caused by particular personality traits, but by their behavioral habits and patterns (Jiang, Jackson, \& Colakoglu, 2016). Organizations may consider providing trainings for managers' 
mental simulation and counterfactual thinking to help them deconstruct the existing cognitive framework, develop entrepreneurial alternatives, and identify novel market opportunities (Gaglio, 2004).

Second, it is helpful for change agents to first map the organizational change journey before prescribing how to manage it. In reality, change agents are often so busy doing daily work that they have no time to recognize the potential chances to be derived from situational momentum. As remarked by Argyris (1997: 304) in his seminal work on organizational learning, 'initiating change requires breaking the self-sealing cycle of defensive beliefs and protective behavior'. Thus, it is necessary for the change agents to consciously and purposefully break down the ongoing routines, to create rhythm-changing events to encourage thorough examination of the environment and to reflect how ongoing schedules need to be adjusted. Temporal breaks can force them to communicate with each other and help them make sense of changes inside and outside their organizations. For example, 'buffer time' in a computer software company helps the engineers review their established patterns of interaction and make sense of how they can adjust their schedules to affect organizational outcomes (Staudenmayer, Tyre, \& Perlow, 2002).

Third, change agents need to go with the flow of organizational change. Van de Ven et al. (1999) adopt the metaphor that an organizational change journey is like that of an uncharted river. Most change agents are clinging to the bank, afraid to let go and risk being carried along by the current of the river. At a certain point, each change agent must be willing to simply let go and trust the river to carry them along safely. At this point, they learn to 'go with the flow' (Gawain, 1982: 29), and the learning journey entails maneuvering through stretches of divergent and convergent waters. In divergent waters, the river branches and expands in multiple dimensions and flows in chaotic or random patterns. Maneuvering these stretches entails divergent exploration, learning by discovery, pluralistic leadership, and running in packs with others to create new relationships and institutions to ensure collective survival. Occasionally the river converges, with internal and external momentum flowing in a particular direction with a more orderly periodic pattern. Many familiar principles of planned change are useful for navigating and exploiting these stretches in an organizational context, including implementing strategic goals, trial-and-error learning, unitary leading, and executing agreements within established institutions for competitive advantage (Van de Ven et al., 1999).

Finally, organizations can set up training programs to help change agents improve their chance management capabilities. It is difficult for agents to recognize a change pattern in the short term. Just when change agents gain some comfort and skill in going with a convergent flow, the change journey may transition again into divergent internal and external patterns that require different managerial skills. This implies that change agents can never obtain full, accurate knowledge about environmental changes, but this does not deny the benefits of their alertness in learning and applying ecological knowledge. Here, the key issues are to analyze the 'deep structure' underlying the internal and external momentum, and comprehend 
the links between past, current, and future momentum (Brown \& Eisenhardt, 1997; Gersick, 1994). To do so, currently, some Chinese companies have begun to adopt strategic reflexivity activities as training programs, such as a 'strategy reviewing program’ (‘战略复盘计划') at Lenovo, a 'strategy maneuvering meeting’ (“战略 推演会') at TCL, and a 'case study meeting' (“案例研讨会') at Haier. Here, the training aims for the change agents to not only understand the contextual impacts of organizational change but also improve their knowledge about how to control the impacts by manipulating the interdependence between their actions and contextual forces. The above management practices need to be examined and popularized in a much broader variety of Chinese companies in the future.

\section{GONGLUSION}

The chance management view presented in this paper offers an inchoate approach to understanding the organizational change process as it is shaped by the interplay of change agents and situational momentum, which have often been taken as isolated mechanisms in the literature. Furthermore, we develop a $2 \times 2$ cell model to illustrate four different timing strategies and related theoretical propositions to help change agents grasp, entrain, ride, or create a favorable chance to change. Here, we are not suggesting that assessing the chance to change is the only aim of organizational change, but we do suggest that researchers take a relational approach to chance when addressing timing issues in a complex organizational context. We believe that this line of study deserves more theoretical and empirical attention.

\section{NOTES}

Thank you to Jia Lin Xie, Senior Editor, and the anonymous reviewers for their constructive feedback and guidance through the review process. Jing thanks the Key Research Project of the National Natural Science Foundation of China (NSFC) (Grant number 71432005) for the financial support on this research.

[1] The planned change view refers to the kind of organizational change theories with a 'philosophical doctrine whose purpose or goal is the final cause for the guiding movement of an entity' (Van de Ven \& Poole, 1995: 515-516).

[2] The two words 'chance' and 'opportunity' may have a slight difference in their meanings, but they are used as synonyms in this study.

[3] Here, as one reviewer has pointed out, Interpretivism exists in both Eastern and Western cultures. Since Aristotle's substance metaphysics, Positivism has been the dominant epistemology in Western society; however, this does not deny the development of Interpretivism as the opposite. For example, the Greek theoretician, Heraclitus, is best known for his doctrines that things are constantly changing, that opposites coincide, and that cosmic fire is the basic material of the world.

[4] We admit that the concept of 'environmental munificence' in strategy management studies also has a sense of meaning in supporting certain strategic actions, as that of 'chance' in present study. But by definition, environmental munificence is a kind of resource attribute (Castrogiovanni, 1991), while chance is a time attribute. Furthermore, as the relational approach has claimed, chance is created by the interaction between internal and external momentum, not just enabled by the external momentum.

[5] We are grateful to the suggestion given by anonymous reviewers here. 


\section{REFERENCES}

Alvarez, S. A., \& Barney, J. B. 2010. Entrepreneurship and epistemology: The philosophical underpinnings of the study of entrepreneurial opportunities. Academy of Management Annals, 4(1): 557-583.

Ancona, D., \& Chong, C. L. 1996. Entrainment: Pace, cycle, and rhythm in organizational behavior. Research in Organizational Behavior, 18: 251-284.

Argyris, G. 1997. Initiating change that perseveres. American Behavioral Scientist, 40(3): 299 309.

Bandura, A. 2005. The evolution of social cognitive theory. In K. G. Smith \& M. A. Hitt (Eds.), Great minds in management: 9-35. Oxford: Oxford University Press.

Baron, R. A. 2006. Opportunity recognition as pattern recognition: How entrepreneurs 'connect the dots' to identify new business opportunities. Academy of Management Perspectives, 20(1): $104-119$.

Baum, J. A. C., \& Shipilov, A. V. 2006. Ecological approaches to organizations. In S. R. Clegg, G. Hardy, T. B. Lawrence, \& W. R. Nord (Eds.), Sage handbook for organization studies: 55-110. London: Sage.

Benford, R. D., \& Snow, D. A. 2000. Framing processes and social movements: An overview and assessment. Annual Review of Sociology, 26: 611-639.

Brown, S. L., \& Eisenhardt, K. M. 1997. The art of continuous change: Linking complexity theory and time-paced evolution in relentlessly shifting organizations. Administrative Science Quarterly, 42(1): 1-34.

Burnes, B. 2011. Introduction: Why does change fail and what can we do about it? Journal of Change Management, 11(4): 445-450.

Burnes, B. 2004. Kurt Lewin and the planned approach to change: A re-appraisal. Journal of Management Studies, 41(6): 977-1002.

Castrogiovanni, G. J. 1991. Environmental munificence: A theoretical assessment. Academy of Management Review, 16(3): 542-565.

Denrell, J., Fang, C., \& Liu, C. 2015. Chance explanations in the management sciences. Organization Science, 26(3): 923-940.

Gaglio, C. M. 2004. The role of mental simulations and counterfactual thinking in the opportunity identification process. Entrepreneurship Theory Practice, 28(6): 533-552.

Gawain, S. 1982. Creative visualization. New York: Bantam.

Gersick, C. J. G. 1994. Pacing strategic change: The case of a new venture. Academy of Management Journal, 37(1): 9-45.

Gibson, J.J. 1954. The visual perception of objective motion and subjective movement. Psychological Review, 61(5): 304-314.

Gibson, J. J. 1977. The theory of affordances. In R. Shaw \& J. Bransford (Eds.), Perceiving, acting, and knowing: Toward an ecological psychology: 67-82. Hillsdale, NJ: Erlbaum.

Gilbert, G. G. 2005. Unbundling the structure of inertia: Resource versus routine rigidity. Academy of Management Journal, 48(5): 741-763.

Glasner, D. 1997. Business cycles and depressions. New York: Garland Publishing Company.

Gollwitzer, P. M. 1999. Implementation intentions: Strong effects of simple plans. American Psychologist, 54(7): 493-503.

Greeno, J. G. 1994. Gibson's affordances. Psychological Revieze, 101(2): 336-342.

Hannan, M. T., \& Freeman, J. H. 1984. Structural inertia and organizational change. American Sociological Revieze, 49(2): 149-164.

Hegel, G. W. F. 1977. Phenomenology of spirit (trans. A. V. Miller). Oxford: Clarendon Press.

Huy, Q. N. 2001. Time, temporal capability, and planned change. Academy of Management Review, 26(4): 601-623.

Jiang, Y., Jackson, S. E., \& Colakoglu, S. 2016. An empirical examination of personal learning within the context of teams. Journal of Organizational Behavior, 37(5): 654672.

Jing, R., \& Van de Ven, A. H. 2014. A 'Yin-yang' model of organizational change: The case of Chengdu Bus Group. Management and Organization Review, 10(1): 29-54.

Jing, R. T., Xie, J. L., \& Ning, J. 2014. Commitment to organizational change in a Chinese context. Journal of Managerial Psychology, 29(8): 1098-1114.

Johns, G. 2006. The essential impact of context on organizational behavior. Academy of Management Review, 31(2): 386-408. 
Jullien, F. 2004. A treatise on efficacy: Between western and Chinese thinking (trans. Janet Lloyd). Honolulu: University of Hawaii Press.

Kirzner, I. M. 1989. Discovery, capitalism, and distributive justice. Oxford: Basil Blackwell.

Kotter, J. P. 1990. What leaders really do. Harvard Business Review, 68(3): 103-111.

Lewin, K. 1951. Field theory in social science: Selected theoretical papers (D. Gartwright, Ed.). New York, NY: Harper \& Brothers.

Lieberman, M. B., \& Montgomery, D. B. 1998. First-mover (dis) advantages: Retrospective and link with the resource-based view. Strategic Management Journal, 19(12): $1111-$ 1125.

Lu, X. H. 2012. Shiyi Pan: An opportunist (in Chinese). The Twenty-First Century, 6: $74-77$.

Mintzberg, H. 1987. Crafting strategy. Harvard Business Revieze, 65(4): 66-75.

Oatley, K., \& Goodwin, B. C. 1971. Explanation and investigation of biological rhythms. In W. P. Colquhain (Ed.), Biological rhythms and human performance. New York: Academic.

Orlikowski, W. J., \& Yates, J. 2002. It's about time: Temporal structuring in organizations. Organization Science, 13(6): 684-700.

Perez-Nordtvedt, L., Payne, G. T., Short, J. C., \& Kedia, B. L. 2008. An entrainment-based model of temporal organizational fit, misfit, and performance. Organization Science, 19(5): 785 801.

Pettigrew, A. M. 2012. Context and action in the transformation of the firm: A reprise. Journal of Management Studies, 49(7): 1304-1328.

Pfeffer, J., \& Salancik, G. R. 2003. The external control of organizations: A resource dependence perspective. Stanford, CA: Stanford University Press.

Piderit, S. K. 2000. Rethinking resistance and recognizing ambivalence: A multidimensional view of attitudes toward an organizational change. Academy of Management Review, 25(4): 783794.

Romanelli, E., \& Tushman, M. L. 1994. Organizational transformation as punctuated equilibrium: An empirical test. Academy of Management Journal, 37(5): 1141-1166.

Rousseau, D. M., \& Tijoriwala, S. A. 1999. What's a good reason to change? Motivated reasoning and social accounts in promoting organizational change. Journal of Applied Psychology, 84(4): 514-528.

Sakakibara, S., Flynn, B. B., Schroeder, R. G., \& Morris, W. T. 1997. The impact of just-in-time manufacturing and its infrastructure on manufacturing performance. Management Science, 43(9): 246-1257.

Sarasvathy, S. D. 2001. Causation and effectuation: Toward a theoretical shift from economic inevitability to entrepreneurial contingency. Academy of Management Revieze, 26(2): 243 263.

Shang, W. X., \& Liu, L. M. 2011. Promised delivery time and capacity games in time-based competition. Management Science, 57(3): 599-610.

Siggelkow, N. 2001. Change in the presence of fit: The rise, the fall, and the renaissance of Liz Claiborne. Academy of Management Journal, 44(4): 838-857.

Sloan, A. 1964. My years with General Motors. Garden City, NY: Doubleday \& Company.

Staudenmayer, N., Tyre, M., \& Perlow, L. 2002. Time to change: Temporal shifts as enablers of organizational change. Organization Science, 13(5): 583-597.

Tsang, E. W. K. 2004. Toward a scientific inquiry into superstitious business decision-making. Organization Studies, 25(6): 923-946.

Van de Ven, A. H., \& Jing, R. 2012. Indigenous management research in China from an engaged scholarship perspective. Management and Organization Review, 8(1): 123-137.

Van de Ven, A. H., Polley, D. E., Garud, R., \& Venkataraman, S. 1999. The innovation journey. New York: Oxford University Press.

Van de Ven, A. H., \& Poole, M. S. 1995. Explaining development and change in organizations. Academy of Management Review, 20(3): 510-540.

Venkataraman, S. 2003. Foreword. In S. Shane (Ed.), A general theory of entrepreneurship: The individual-opportunity nexus: $x$ i-xii. Northampton, MA: Edward Elgar.

von Franz, M. L. 1980. On divination and synchronicity: The psychology of meaningful chance. Toronto, CA: Inner City Books.

Zhang, X. J., Fu, P. P., Xi, Y. M., Li, L., Xu, L. G., Cao, C. H., Li, G. Q., Ma, L., \& Ge, J. 2012. Understanding indigenous leadership research: Explication and Chinese examples. Leadership Quarterly, 23(6): 1063-1079. 
Runtian Jing (rtjing@sjtu.edu.cn) is a professor of organizational management in the Antai College of Economics and Management of the Shanghai Jiao Tong University. He received his PhD from the Xi'an Jiao Tong University in 1997, and taught at the University of Electronic Science and Technology of China before his present appointment. His research focuses on organizational change and leadership behaviour. He was granted the Award of Yangtze River Young Scholars Distinguished Professor by the Ministry of Education of China.

Andrew Van de Ven (avandeve@umn.edu) is the Vernon Heath Professor of Organizational Innovation and Change at the University of Minnesota. He received his $\mathrm{PhD}$ from the University of Wisconsin, and taught at Kent State University and the Wharton School of the University of Pennsylvania before his present appointment. He teaches courses on the management of innovation and change, organizational behavior, and engaged scholarship. He is co-author of 12 books, including Engaged Scholarship (2007), which won the 2008 AOM Terry Award.

Manuscript received: March 22, 2015

Final version accepted: May 25, 2017 (number of revisions - 3)

Accepted by: $\quad$ Senior Editor Jia Lin Xie 